"Y que un bello cuadro es una eyaculación». Género en el discurso invencionista Ayelén Pagnanelli

Boletín de Arte (N. $\left.{ }^{\circ} 21\right)$, e032, abril 2021, ISSN 2314-2502

https://doi.org/10.24215/23142502e032

http://papelcosido.fba.unlp.edu.ar/ojs/index.php/boa

Facultad de Artes. Universidad Nacional de La Plata

La Plata. Buenos Aires. Argentina

\title{
"Y QUE UN BELLO CUADRO ES UNA EYACULACIÓN» GÉNERO EN EL DISCURSO INVENCIONISTA
}

\section{«AND THAT A BEAUTIFUL PAINTING IS AN EJACULATION»}

\author{
GENDERING INVENTIONIST DISCOURSE
}

Ayelén Pagnanelli / apagnanelli@unsam.edu.ar

Consejo Nacional de Investigaciones Científicas y Técnicas (CONICET)

Centro de Investigaciones en Arte y Patrimonio. Universidad Nacional de San Martín. Argentina

\section{RESUMEN}

En este artículo se analiza, desde una perspectiva de género, el discurso invencionista. Intenta desmontar el androcentrismo de la propuesta plástica del arte abstracto en Buenos Aires desde mediados de la década de 1940. Examina textos teóricos y poéticos producidos por los grupos de abstracción Asociación Arte Concreto-Invención y Madí $y$, en particular, la revista Arturo. Se sugiere que mediante el uso de conceptos como proceso artístico, pureza y neutralidad sexual, los artistas de la abstracción construyeron un discurso androcéntrico que consideraba a los varones como productores ideales de las obras.

\section{PALABRAS CLAVE}

Género; arte abstracto; invencionismo; discurso

\begin{abstract}
This article analyzes gender in the inventionist discourse. It attempts to dismantle androcentrism in the abstract art from Buenos Aires in the 1940s. It examines theoretical and poetic texts produced by the abstraction groups Asociación Arte Concreto-Invención and Madí and, in particular, the content of Arturo magazine. It is suggested that through the use of concepts such as artistic process, purity and sexual neutrality, male artists produced an androcentric discourse that considered men as the ideal producers of oeuvre.
\end{abstract}

\section{KEYWORDS}

Gender; abstract art; invencionism; discourse 
Cuando en uno de los únicos textos teóricos escritos por mujeres publicados en las revistas de los grupos de abstracción la artista y poeta Diyi Laañ (1954) indicó que «nada revela tanto la geografía espiritual de la narración como el deseo de infundir acción" (p. 21), parecía reflexionar sobre la abundante producción teórica que la abstracción local generó al apuntalar su producción plástica. Les artistas invencionistas, tanto varones como mujeres, desde mediados de la década de 1940, se abocaron a la propuesta plástica de una abstracción cuya radicalidad yacía en que su obra era tajantemente no figurativa.

La primera acción en el medio local de estes jóvenes artistas fue la publicación de la mítica Arturo, Revista de Artes Abstractas en 1944. El comité editor estaba conformado por Edgar Bayley, Gyula Kosice, Rhod Rothfuss y Carmelo Arden Quin; las viñetas fueron realizadas por Lidy Prati quien firmó como Lidy Maldonado y la tapa por Tomás Maldonado, su esposo y el hermano menor de Bayley. Hacia 1946, quienes habían armado Arturo formaron nuevas agrupaciones con la incorporación de más artistas: Madí, la Asociación Arte Concreto Invención (AACl) y, en 1947, Perceptismo, como un desprendimiento de este último grupo.

Más allá de las divisiones, estes artistas compartían un núcleo de intereses y de abordajes a problemas plásticos. El concepto de invención estuvo en el centro de muchas de estas exploraciones y fue desarrollado en la producción teórica de estos artistas desde Arturo (García, 2011; Crispiani, 2011). Dado que las obras fueron abstractas y no figurativas, el análisis de la producción teórica resulta indispensable para advertir cómo operó el género en estos grupos de abstracción. Estos artistas teorizaron profusamente sobre su práctica, de hecho, María Amalia García (2011) ha advertido que "la importancia otorgada a la constitución teórico-discursiva de los proyectos hace pensar que, por momentos, este aparato tuvo mayor protagonismo que la obra plástica» (p. 55). Debido a la necesidad de enmarcar discursivamente esta obra rupturista, los artistas invencionistas se inscribieron en la práctica modernista de producir teoría (Beckett, 1983) y es allí donde sus ideas sobre el género se revelan.

Los textos publicados en estas revistas mayormente fueron aquellos escritos, o al menos firmados, por varones. En Arturo, en Arte Madí y en las publicaciones de la $\mathrm{AACl}$, proyectaron una obra abstracta, no figurativa, pura y sexualmente neutra confiando en que estas transformasen al mundo en una utopía en clave socialista. En este trabajo se sostiene que el discurso producido por los artistas varones ${ }^{1}$ de la abstracción fue androcéntrico y que conceptualizó a los varones como los productores ideales de las obras.

El arte abstracto producido en la Argentina entre 1940 y 1960 ha sido estudiado desde numerosos ángulos, sin embargo, la perspectiva de género ha permanecido prácticamente ausente. Se destacan a una serie de investigaciones que se han centrado en estos grupos en cuanto a sus redes regionales (García, 2011; Rossi, 2004), su militancia política (Lucena, 2015), la conformación de las agrupaciones artísticas (Pérez-Barreiro, 1996) y la conformación de colecciones (García, 2017; Pérez-Barreiro, 2007). Otras se han centrado en el análisis de las revistas producidas en ese período ya que representan un espacio privilegiado para explorar los discursos de estos grupos (García, 2018; García \& Dolinko, 2018; Derek, 1994). Algunas investigaciones han abordado la producción teórica en relación con la teoría marxista (Crispiani, 2011) y las teorías científicas (Siracusano, 1995). Estas investigaciones han sido fundamentales para comprender y complejizar los procesos y la producción teórico-discursiva de esos años. Este artículo intenta desmontar el androcentrismo de esa propuesta discursiva invencionista. Se inscribe como parte de la historia feminista del arte, iniciada con las críticas de Linda Nochlin (1971) y Griselda Pollock (y Rozsika Parker) [1981] (2013) en la academia anglosajona, y en el medio local con los trabajos de Laura Malosetti Costa (2000) y, más recientemente, de Georgina Gluzman (2016), de Andrea Giunta (2018) y de María Laura Rosa

1 Con relación al uso de los términos masculino y varones como sinónimos en este artículo, se refiere a las concepciones que emergen de los textos analizados en las que varones indica a varones cis. 
(2014). Destacamos el ensayo de García (2009) ya que nota que el discurso invencionista estaba atravesado por ideas sobre el género. A diferencia de varias de estas investigaciones, el presente trabajo desplaza su mirada hacia los artistas varones, ya que fueron quienes produjeron el discurso invencionista ${ }^{2}$.

Primero se examina cómo los artistas vincularon la abstracción no figurativa a la pureza. Segundo, se traza cómo se llegaba a dicha pureza tras un proceso artístico cuasi científico que depuraba los elementos considerados femeninos. Ideas que, en parte, retomaron de textos de la abstracción de las vanguardias europeas de la primera mitad del siglo Xx. Tercero, se analiza cómo detrás de la pureza se encuentra una concepción del arte abstracto como masculino y ejecutado por varones.

\section{LA PUREZA Y LA ABSTRACCIÓN NO FIGURATIVA}

En varios de los textos teóricos invencionistas encontramos referencias a un concepto de pureza que parece referir a la falta de figuración. En el manifiesto Madí (1947), se unen las nociones de pureza de la obra de arte abstracta a la no figuración de manera explícita: "CON LO CONCRETO [...] se inicia el gran período del Arte No Figurativo, donde el artista, sirviéndose del elemento y su respectivo continuo, crea la obra en toda su pureza, sin hibridaciones y objetos extraños a su esencia» (s. p.).

En el manifiesto, la no figuración conforma la pureza del arte Madí. Este manifiesto fue publicado en la revista Arte Madí 0-1, ${ }^{3}$ la cual tuvo ocho números entre 1947 y 1954 . Encontramos una referencia similar en Literatura de vanguardia, libro de Juan Jacobo Bajarlía publicado en 1946. Bajarlía era cercano a Edgar Bayley, teórico del invencionismo y miembro de la $\mathrm{AACl}$. En su texto, consideraba que el invencionismo debía ser no-figurativo y, firmemente, lo asociaba a la pureza.

La novísima tendencia del invencionismo estético, brotó de una necesidad imperativa: crear un arte puro, que existiera por sí mismo sin puntos de contacto con otras escuelas figurativas. Un arte en el que la realidad fuera inventada por encima de todas las realidades conocidas. Y con esta imposición de pureza, de autonomía estética, casi científica, se amalgamaba una relación dialéctica [...] (Bajarlía, 1946, p. 160).

Bajarlía describe a la pureza como la autonomía estética sin influencia de lo figurativo y como casi científica. Estimaba a la pureza y a la cientificidad como valores a los cuales alcanzar. La pureza se exhibe como absolutamente necesaria para el arte abstracto.

Si bien tuvieron diferencias entre sí, los grupos de abstracción en el discurso invencionista apelaron al concepto de pureza. Lo asociaron al arte no figurativo que formaba parte de su producción plástica, y también lo relacionaron a la ciencia.

\section{EL PROCESO ARTÍSTICO COMO METÁFORA CIENTÍFICA}

Para los artistas de las vanguardias europeas de principios del siglo XX, la pureza de la no figuración se adquiría mediante un proceso de depuración. Michel Seuphor (en Faxedas, 2015), uno de los líderes de Cercle et Carré, movimiento de arte abstracto conformado en 1929 en París junto con el artista uruguayo Joaquín Torres García, sostuvo:

2 Presenta parte de los resultados de la tesis de maestría Arte abstracto argentino: una lectura de género (Buenos Aires, 1944-1954) (2019) defendida en el Instituto de Altos Estudios Sociales (IDAES) de la Universidad Nacional de San Martín (UNSAM). La tesis examina el discurso invencionista, las prácticas de masculinidad hegemónicas de algunos de los protagonistas de los grupos del arte abstracto de ese período y la producción y las experiencias de las mujeres que participaron de esa escena artística.

3 Para el detalle de la discusión sobre la autoría del manifiesto Madí, véase The Argentine Avant-Garde: 1944 1950 [La vanguardia argentina: 1944-1950] (1996), de Gabriel Pérez-Barreiro. 
[...] dos nociones generales crean toda la naturaleza: lo bello y lo verdadero [...]. Todo hombre está igualmente atraído a estas dos nociones del mundo: por un lado el principio, lo deliberado, lo vertical, y por el otro lado, lo natural, lo femenino, horizontal [...]. La belleza natural nos lleva de la mano al corazón de la materia mientras que la atracción a lo verdadero nos incita a pensar y nos eleva a la abstracción (p. 40). ${ }^{4}$

Seuphor conceptualizó sus ideas sobre el arte abstracto con metáforas generizadas. Lluïsa Faxedas (2015) ha identificado que el discurso de Seuphor "favorecía las dimensiones espirituales, mentales e intelectuales de la existencia que se corresponden a lo masculino en detrimento de las dimensiones materiales, naturales o sensuales de la existencia, es decir, lo femenino" (p. 40). ${ }^{5}$ La epistemología feminista ha analizado extensamente la jerarquización de los elementos categorizados como masculinos. El androcentrismo como forma de pensamiento coloca su eje sobre el sujeto a un varón específico (adulto, blanco, colonial, heterosexual y burgués) representado simbólicamente como superior al resto de les humanos (Maffía, 2007; Lugones, 2014; Fabbri, 2014). El uso del lenguaje de Seuphor en este fragmento sobre la depuración de lo femenino apuntaba a privilegiar discursivamente aquello que se estimaba masculino.

Similarmente, Piet Mondrian (en Faxedas, 2013), cofundador de De Stijl junto con Theo van Doesburg, instó a un proceso en el cual lo femenino debía abandonarse en la abstracción:

La sabiduría ancestral identifica lo físico, lo natural con lo femenino y lo espiritual con el elemento masculino [...]. Por esto es solo necesario que la nueva mentalidad se desarrolle libremente: que aniquile la antigua mentalidad y la dominación del elemento individual, natural (o femenino) (p. 34). ${ }^{6}$

Mondrian manifestó más abiertamente la conexión entre lo espiritual y lo mental como asociada a lo masculino. Ambas citas hermanan lo bello, lo racional y lo cultural a lo masculino. Según Faxedas (2015), la visión de Seuphor de que se debía depurar el elemento trágico —relacionado al cuerpo femenino- llevó a los artistas de Cercle et Carré a apoyar una llamada abstracción pura. Esta abstracción pura estaba directamente asociada a los varones y lo masculino. Así, en estos fragmentos del discurso del arte abstracto europeo se unieron y se privilegiaron la pureza y lo masculino.

Los artistas invencionistas recurrieron discursivamente a un proceso de depuración de lo femenino en sus escritos. Entendemos que esta apropiación de aspectos del discurso de los artistas de vanguardia europeos se dio en un contexto de continuidad creativa por sobre lo propuesto en Europa y no de mera copia (Giunta, 2020).

Ya en Arturo aparecieron referencias a un proceso de depuración. El artista uruguayo Carmelo Arden Quin (1944), quien luego formó parte de Madí, escribió:

4 "Two generalized notions make up the whole of nature: the beautiful and the true [...]. Every man is equally attracted to these two notions of the world: on the one hand, the principle, the deliberate, the vertical, and on the other hand, the natural, the femenine, the horizontal [...]. Natural beauty takes us gently by the hand and leads us to the heart of matter, whereas the attraction of the true incited us to thought and lifts us to abstraction" (Seuphor en Faxedas, 2015, p. 40). Traducción de la autora del artículo.

5 "[...] favor the spiritual, mental, and intellectual dimensions of existence (corresponding to the masculine), in detriment to the material, natural, or sensual dimensions (that is, the femenine)" (Faxedas, 2015, p. 40). Traducción de la autora del artículo.

6 "Ancient wisdom identified the physical, the natural, with the female, and the spiritual with the male element [...]. For this, it is only necessary that the new mentality develops freely: that it anhilites [sic] the old mentality and domination by the individual, natural (or female) element" (Mondrian en Faxedas, 2013, p. 34). Traducción de la autora del artículo. 
El automatismo no dió [sic] nunca una criatura viva. Ha dado fetos. En buena hora el automatismo para despertar la imaginación. Pero inmediatamente recobrarse e incidir sobre él con una alta conciencia artística y cálculos, incluso fríos, pacientemente elaborados y aplicados. Automáticamente devendrá ello creación.

Así la invención se hace rigurosa, no en los medios estéticos, sino en los fines estéticos. Esto, naturalmente, implica primero la imaginación aflorando en todas sus contradicciones; y luego la conciencia ordenándola y depurándola de toda imagen representativa naturalista (aunque sea de sueños), y de todo símbolo (aunque sea subconsciente) (s. p.).

Para Arden Quin el arte requería de un frío proceso racional, científico y matemático para depurarlo de toda imagen naturalista; esto diferenciaba la invención del resto del arte, especialmente del automatismo surrealista. Así, delineó los pasos de un proceso artístico de depuración, similar al propuesto por Seuphor, el cual hace un paralelo metafórico con el método científico.

La idea de ciencia a la que apeló Arden Quin se anclaba en lo masculino. Donna Haraway (1997) ha demostrado cómo los cuerpos de los varones se convirtieron en la norma en la ciencia. Estos se construyeron sin estar marcados por su género, cultura o historia, y se cimentaba una idea de ciencia fuertemente signada por la presunción de objetividad y ligada a sus cuerpos. La ciencia se pensaba como objetiva y quienes la practicaban, los varones científicos, se volvían al mismo tiempo objetivos y figuras de autoridad.

Los artistas invencionistas teorizaron sobre el arte abstracto apropiándose de aspectos del discurso del arte abstracto europeo de principios del siglo xx. Utilizaron la metáfora del proceso artístico como científico, lo cual los acercaba a la legitimidad que la ciencia conceptualizada como masculina podía brindarle a su propuesta artística.

\section{EL ARTE ABSTRACTO COMO MASCULINO Y PRODUCIDO POR VARONES}

Parte de la producción teórica invencionista se alineó a la idea de que el arte que produjera debía ser sexualmente neutro. Sin embargo, los artistas no imaginaron su producción por fuera de las ideas jerarquizadas de los géneros. En su discurso, este formalismo no figurativo encubría a un sujeto varón como productor de las obras. Bajarlía (en García, 2009) realizó una descripción de la obra que estos artistas estipulaban crear:

Los expositores de Peuser [...]. Continuaron sus investigaciones y establecieron nuevos principios. Deshecharon el plano unitario y arremetieron contra la curva. Su estética debía presentar obras asexuadas y no era conveniente que una arista cóncava o convexa diera la imagen, una pátina figurativa de un estado físico personal. Aparecía el macho y la hembra, según su colocación en el plano y estarían contra los postulados del concepto puro (p. 96).

La pureza a la que Bajarlía refiere se conseguiría a través de la neutralidad sexual de las obras. A su vez, se accedería a la neutralidad evitando las líneas curvas, ya que, según este autor, sugerirían sexo. En este sentido, planteaba que este conjunto de artistas arremetió contra la curva. Utilizó el verbo arremeter, asociado con un fuerte ímpetu, para establecer que el elemento de la construcción visual de las obras abstractas debía ser la línea recta.

En este fragmento se aspira a una abstracción pura y neutral. Realizar algún tipo de referencia que aluda a la idea de hombre o mujer era contraproducente a esa búsqueda de pureza, del concepto puro. No se refiere siquiera a cuerpos humanos, sino a que las líneas del plano sugieran cuerpos sexuados. García (2009), sobre este fragmento, ha analizado que "la caracterización de "obras sexuadas" como la lucha contra las connotaciones físicas y espirituales de la curva permiten releer las ideas concretistas, aparentemente "puras" y sin género, a la luz del canon enunciativo de la masculinidad occidental» (p. 96). El concepto puro 
al que apunta Bajarlía se alcanzaría mediante una obra conformada por líneas rectas, la cual sería asexuada y neutral en términos de género. Esta neutralidad tras la cual la epistemología feminista encuentra encubierta la figura del sujeto varón.

Una instancia en la cual fue explícito que el género en el discurso aparentemente neutral del arte abstracto argentino era el masculino fue en el poema "Segundo Poema en Ción" (1944), de Edgar Bayley, publicado en Arturo. Leer con perspectiva de género este poema permite comprender que en el discurso invencionista los autores tenían en mente un artista que fuese varón. Bayley publicó un texto teórico y tres poemas en Arturo: Estreno Escurre, "Primer poema en Ción" y "Segundo poema en Ción". Fechado en marzo de 1944, en "Segundo poema en Ción" se lee:

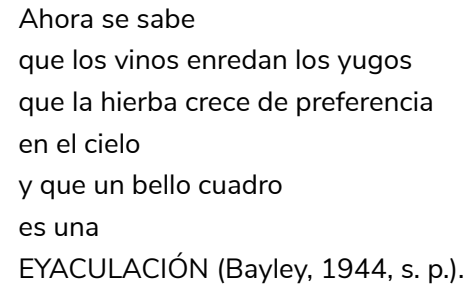

Esta cita conecta las ideas de belleza y de arte con el fluido sexual de un varón de forma explícita en un temprano texto invencionista. Este poema de Bayley y en particular estos versos han llamado la atención de varias autoras. Sin embargo, no los han analizado detenidamente ni han advertido en las implicancias que tienen en términos de género para el discurso invencionista.

En el 2003, la historiadora del arte Adriana Lauria incluyó algunos versos del poema en su texto "Arte abstracto en la Argentina. Intermitencia e instauración" publicado en el catálogo de la exhibición Arte abstracto argentino. Reprodujo los versos finales del poema como un epígrafe al final de su ensayo, titulando al poema "Eyaculación». En la revista Arturo el título del poema se lee en la parte superior de la página "Segundo poema en Ción". La autora no ofreció los motivos del cambio de título. Al utilizar al poema como epígrafe, Lauria no realizó un análisis de los versos reproducidos como tampoco del uso del vocablo eyaculación.

Por su parte, Ornela Barisone (2017) señaló algunos aspectos formales del poema como la repetición de letras y el uso de mayúsculas en la palabra eyaculación, recursos que relacionó con la poética de Oliverio Girondo. No obstante, no indicó si los aspectos de la producción de Girondo que se vincularían con Bayley son formales —el uso de mayúsculas - o temáticos — prácticas sexuales-. De hecho, Girondo (1968) se refirió a la sexualidad masculina en su producción y hasta utilizó el verbo eyacular en su poema de 1920 «Exvoto: a las chicas de flores". Barisone menciona estos versos de Bayley sin adentrarse profundamente en su análisis.

En cambio, Luciana del Gizzo (2017) ha propuesto un análisis de los versos aquí citados de "Segundo poema en Ción". Sugirió que la idea de eyaculación es contradictoria con lo que estima fueron los planteos del arte concreto. Según la autora, este arte plantearía que es "fundamental la planificación racional de la obra" y que lo que Bayley uprocura resaltar es la naturaleza inevitablemente orgánica del arte» (Del Gizzo, 2017, p. 94). La propuesta estética en Arturo fue más ecléctica de lo que luego fueron las producciones de les artistas que produjeron la revista; el énfasis en Arturo no estuvo únicamente orientado a la racionalidad del arte (García, 2018). Por este motivo, no hay contradicción alguna entre las propuestas invencionistas de 1944 y esta frase tal como postuló Del Gizzo. Lo orgánico aún estaba contemplado como opción válida para la abstracción. Incluso, la racionalidad no es opuesta a la eyaculación. Al contrario, la eyaculación y la racionalidad son ambas potestad de los varones. De las tres autoras que han mencionado este poema en sus trabajos ninguna lo 
asocia directamente a los cuerpos de los varones, a su idea del artista y del arte, o a la concepción de la belleza.

Los versos resaltados de "Segundo poema en Ción" dan cuenta de la propuesta plástica que proponían quienes hicieron Arturo, ya que, como se mencionó anteriormente, conectan las ideas de belleza y de arte con el fluido sexual de un varón de manera explícita en la publicación que aglutinó tempranamente a la abstracción en la Argentina. La palabra eyaculación es central en el poema. Está en mayúsculas, tiene su propio verso solo para ella y se encuentra justo en el centro de la página. Resalta a simple vista de la página, como se observa en la Figura 1. Estos versos revelan que los artistas invencionistas pensaban a los productores de sus obras como varones. Se entiende que Bayley tenía en mente a un artista varón como creador de la pintura invencionista, ya que utiliza la metáfora del pene como pincel: el artista (varón) pinta la obra mediante un pincel que aquí se reemplaza por su pene haciendo, entonces, a la pintura una huella de su semen. Anuncia que son únicamente los varones quienes podrán producir bellas pinturas.

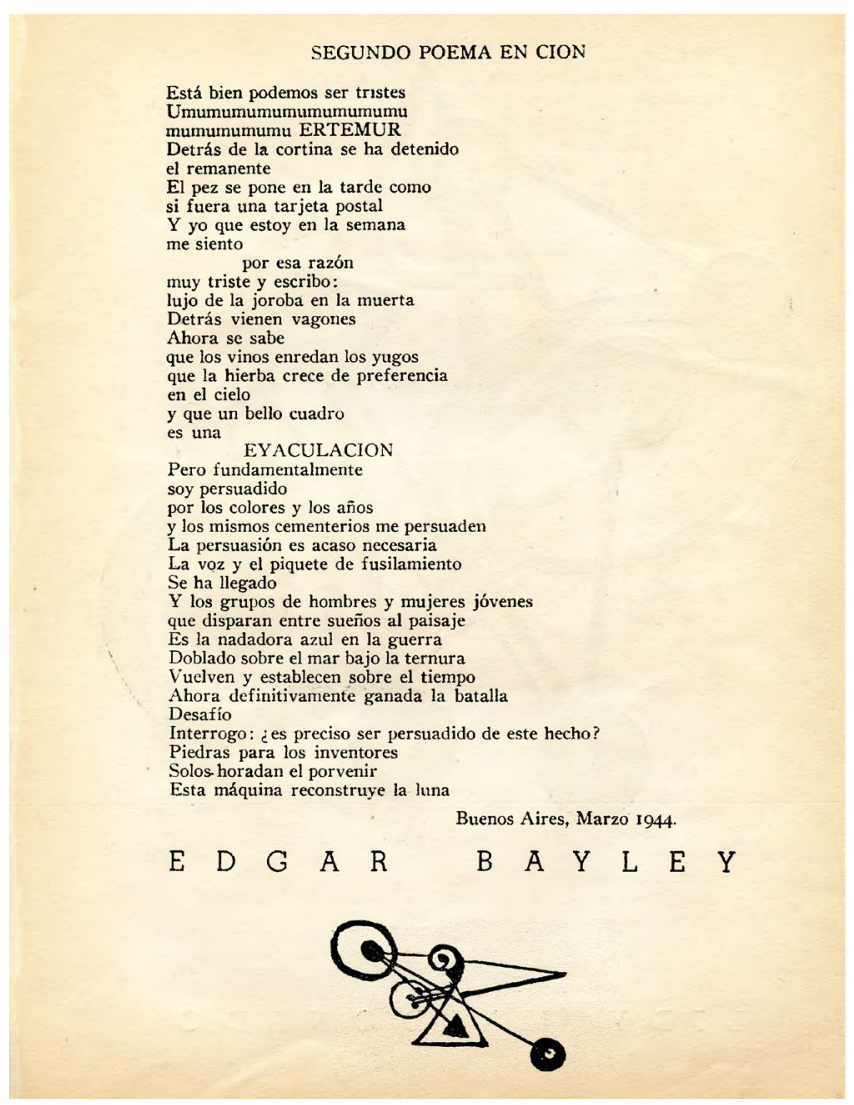

Figura 1. , «Segundo poema en Ción» (1944, Edgar Bayley)

Bayley, en "Segundo poema en Ción", colocó a los cuerpos de los varones en el centro de la producción plástica invencionista. Ubicó a este incipiente movimiento artístico para que no pueda ser catalogado como femenino. El análisis de este poema de Bayley sugiere que la vanguardia invencionista reforzó la idea del artista como un varón.

De este modo, las ideas que aparecen en el discurso invencionista sobre crear un arte sexualmente neutro y puro, producido mediante un proceso científico, deben ser pensadas como estrategias de estos artistas para acercarse a lo masculino, ya que poseía mayor legitimidad. Este discurso retomó algunos aspectos de la producción teórica de artistas europeos como Seuphor, Mondrian y Van Doesburg. El género estuvo presente en el discurso del arte abstracto en Buenos Aires desde la segunda mitad de la década de 1940. 
Discursivamente, se evocó a un arte puro y científico que eliminara cualquier vestigio figurativo, ya que lo asociaban a lo femenino. Encubría así a un sujeto varón como productor de las obras abstractas y al androcentrismo de la propuesta invencionista. Las voces de las artistas se encuentran prácticamente ausentes en esta producción teórica. Este discurso, lejos de quedar meramente en lo textual, tuvo consecuencias materiales en las vidas y en las trayectorias, especialmente, de las artistas que participaron de esta escena.

\section{REFERENCIAS}

Del manifiesto de la Escuela. (1947). Arte Madí Universal, (0).

Arden Quin, C. (1944). Son las condiciones. Arturo.

Bajarlía, J. J. (1946). Literatura de vanguardia. Del "Ulises» de Joyce a las escuelas poéticas. Ciudad Autónoma de Buenos Aires, Argentina: Araujo.

Barisone, O. (2017). Experimentos poéticos opacos: biopsias malditas: del invencionismo argentino a la poesía visual 1944-1969. Ciudad Autónoma de Buenos Aires, Argentina: Corregidor.

Bayley, E. (1944). Segundo poema en Ción. Arturo.

Beckett, J. (1983). Discoursing on Dutch Modernism [Generando discurso sobre el modernismo holandés]. Oxford Art Journal, 6(2), 67-79.

Crispiani, A. (2011). Objetos para transformar el mundo: trayectorias del arte concretoinvención, Argentina y Chile 1940-1970: la escuela de arquitectura de Valparaíso y las teorías del diseño para la periferia. Bernal, Argentina: Universidad Nacional de Quilmes; Ciudad Autónoma de Buenos Aires, Argentina: Prometeo 30/10; Santiago de Chile, Chile: ARQ.

Del Gizzo, L. (2017). Volver a la vanguardia. Ciudad Autónoma de Buenos Aires, Argentina: En Danza.

Derek, H. (1994). The Place of Arturo in the Argentinian Avant-Garde [El lugar de Arturo en la vanguardia argentina]. Aberdeen, Reino Unido: University of Aberdeen.

Fabbri, L. (2014). Desprendimiento androcéntrico. Pensar la matriz colonial del poder desde los aportes de Silvia Federici y María Lugones. Universitas Humanística, 78(78), 89107. Recuperado de https://revistas.javeriana.edu.co/index.php/univhumanistica/article/ view/6415

Faxedas, M. L. (2013). ¿Contra sí mismas? Mujeres artistas en los orígenes de la abstracción. Brac: Barcelona, Research, Art, Creation, 1(1), 27-61.

Faxedas, M. L. (2015). Women Artists of Cercle et Carre. Abstraction, Gender and Modernity [Mujeres artistas de Cercle et Carre. Abstracción, género y modernidad]. Women's Art Journal, 36(1), 37-46.

García, M. A. (2009). Lidy Prati y su instancia diferencial en la unidad del arte concreto. En Yente-Prati (pp. 87-100). Ciudad Autónoma de Buenos Aires, Argentina: Fund. Eduardo F. Costantini.

García, M. A. (2011). El arte abstracto: intercambios culturales entre Argentina y Brasil. Ciudad Autónoma de Buenos Aires, Argentina: Siglo Veintiuno.

García, M. A. (2017). Episodios Colección Pirovano. En M. A. García (Ed.), Legado Pirovano: la colección Ignacio Pirovano en el Moderno (pp. 19-27). Ciudad Autónoma de Buenos Aires, Argentina: Museo de Arte Moderno de Buenos Aires.

García, M. A. (2018). La revista Arturo y la potencia múltiple de la vanguardia. En M. A. García (Comp.), Edición facsimilar de la revista Arturo: ensayos y traducciones (pp. 7-20). Ciudad Autónoma de Buenos Aires, Argentina: Fundación Espigas.

García, M. A. y Dolinko, S. (2018). Círculo de revistas. Interlocución entre publicaciones de la modernidad visual latinoamericana. Goya, (363), 142-159.

Girondo, O. (1968). Exvoto: a las chicas de flores. En Obras completas. Ciudad Autónoma de Buenos Aires, Argentina: Losada.

Giunta, A. (2018). Feminismo y arte latinoamericano. Ciudad Autónoma de Buenos Aires, Argentina: Siglo Veintiuno. 
Giunta, A. (2020). Contra el canon. Ciudad Autónoma de Buenos Aires, Argentina: Siglo Veintiuno.

Gluzman, G. (2016). Trazos invisibles: mujeres artistas en Buenos Aires, 1890-1923. Ciudad Autónoma de Buenos Aires, Argentina: Biblos.

Haraway, D. (1997). Modest_Witness@Second_Millennium. FemaleMan_Meets_OncoMouse [Testigo_modesto@Segundo_milenio. HombreHembra_conoce_Oncoratón]. Nueva York, Estados Unidos: Routledge.

Laañ, D. (junio de 1954). Prosa y relato. Arte Madí Universal, (7-8), 21.

Lauria, A. (2003). Arte abstracto en la Argentina. Intermitencia e instauración. En M. Pacheco (Ed.), Arte abstracto argentino (pp. 22-47). Ciudad Autónoma de Buenos Aires, Argentina: PROA.

Lucena, D. (2015). Contaminación artística. Vanguardia concreta, comunismo y peronismo en los años 40. Ciudad Autónoma de Buenos Aires, Argentina: Biblos.

Lugones, M. (2014). Colonialidad y género. En K. Ochoa Muñoz, Y. Espinosa Miñoso, D. Gómez Correal (Eds.), Tejiendo de otro modo. Feminismo, epistemología y apuestas descoloniales en Abya Yala (pp. 57-73). Cauca, Colombia: Universidad del Cauca.

Malosetti Costa, L. (2000). Una historia de fantasmas. Artistas plásticas de la generación del ochenta en Buenos Aires. Ponencia presentada en las $6 .^{\circ}$ Jornadas de Historia de las Mujeres y $1 .^{\circ}$ Congreso Iberoamericano de Estudios de las Mujeres y de Género. Instituto Interdisciplinario de Estudios de Género de la Facultad de Filosofía y Letras, Universidad de Buenos Aires, Ciudad Autónoma de Buenos Aires, Argentina.

Maffía, D. (2007). Epistemología feminista. La subversión semiótica de las mujeres en la ciencia. Revista Venezolana de Estudios de la Mujer, 12(28), 63-98.

Nochlin, L. (1971). Why Have There Been No Great Women Artists? [¿Por qué no ha habido grandes mujeres artistas?]. Artnews.

Pagnanelli, A. (2019). Arte abstracto argentino: una lectura de género (Buenos Aires, 19441954) (Tesis de maestría). Recuperado de https://ri.unsam.edu.ar/handle/123456789/1106

Pérez-Barreiro, G. (1996). The Argentine Avant-Garde: 1944-1950 [La vanguardia argentina: 1944-1950] (Tesis de doctorado). Department of Art History and Theory, University of Essex, Reino Unido.

Pérez-Barreiro, G. (2007). The Geometry of Hope: Latin American Abstract Art from the Patricia Phelps De Cisneros Collection [La geometría de la esperanza: Arte abstracto latinoamericano de la Colección Patricia Phelps De Cisneros]. Austin, Estados Unidos: Blanton Museum of Art, University of Texas at Austin.

Pollock, G. y Parker, R. [1981] (2013). Old Mistresses. Women, Art and Ideology [Grandes maestras. Mujeres, arte e ideología]. Londres, Reino Unido: I. B. Tauris.

Rosa, M. L. (2014). Legados de libertad. El arte feminista en la efervescencia democrática. Ciudad Autónoma de Buenos Aires, Argentina: Biblos.

Rossi, C. (2004). En el fuego cruzado entre el realismo y la abstracción. En Arte Argentino y latinoamericano del siglo XX: sus interrelaciones (pp. 83-126). Ciudad Autónoma de Buenos Aires, Argentina: Fondo para la Investigación del Arte Argentino (FIAAR), Fundación Espigas.

Siracusano, G. (1995). En búsqueda del paradigma oculto: una reflexión sobre la obra y el universo epistémico de Raúl Lozza. En El arte entre lo público y lo privado. VI Jornadas de Teoría e Historia del Arte (pp. 359-369). Ciudad Autónoma de Buenos Aires, Argentina: CAIA. 